DOI: $10.15421 / 4219024$

УДК 539.3

\author{
Е. Л. Гарт, д-р фоз.-мат. наук, Б. І. Терьохін
}

\title{
ВИБІР РАЦІОНАЛЬНИХ ПАРАМЕТРІВ ПІДКРІПЛЮЮЧИХ ЕЛЕМЕНТІВ ПРИ КОМП'ЮТЕРНОМУ МОДЕЛЮВАННІ ПОВЕДІНКИ ЦИЛІНДРИЧНОЇ ОБОЛОНКИ 3 ДВОМА ПРЯМОКУТНИМИ ОТВОРАМИ
}

Досліджено напружено-деформований стан тонкостінної циліндричної оболонки 3 двома прямокутними отворами та чотирма видами включень. На основі проведеного скінченно-елементного аналізу визначено вплив форми, розмірів та матеріалу включень на напружено-деформований стан оболонки в місцях локальних концентраторів напружень. Подано рекомендації щодо зниження концентрації напружень.

Ключові слова: тонкостінна циліндрична оболонка, прямокутні отвори, включення, підкріплення, напруження, деформації, коефріцієнт концентрації напружень, метод скінченних елементів.

Вступ. Пластини і оболонки, як елементи тонкостінних конструкцій, знайшли широке застосування в різноманітних галузях техніки, енергетиці, будівництві та ін. В інженерній практиці широке розповсюдження знаходять такі конструкції, як цистерни, водонапірні резервуари, газгольдери, повітряні і газові балони, апарати хімічного машинобудування, частини корпусів турбін і реактивних двигунів, куполи будинків та ін. Усі ці конструкції з погляду їх розрахунку на міцність і жорсткість можуть бути віднесені до тонкостінних оболонок.

За різних - конструктивних або технологічних міркувань, в них часто порушується суцільність різного роду отворами. В близькості від отворів виникають локальні (додаткові) напруження, які можуть у кілька разів перевищувати основні напруження в елементі, неослабленому концентратором. При певних умовах це ініціює руйнівні процеси.

При застосуванні навколо отворів включень, різних геометричних форм і механічних властивостей, з'являється можливість впливати на розподіл напружень в елементі конструкції, зокрема, на величину коефіцієнта концентрації напружень (ККН). Врахування наявності такого роду суттєвої неоднорідності матеріалу, у свою чергу, призводить до підвищення складності математичної моделі задачі. Знаходження точного розв'язку отриманої крайової задачі в аналітичному вигляді можливо лише в деяких окремих випадках навантаження тіл та при окремих умовах їх закріплення $[5,8,10]$.

Тому при досліджені напружено-деформованого стану (НДС) конструкцій з різними неоднорідностями (отворами, виточками, включен-

() Е. Л. Гарт, Б. І. Терьохін, 2019 
нями тощо) доцільно використовувати числові методи механіки, які, на відміну від аналітичних, є досить універсальними і ефективними для розв'язування широкого класу задач [2 - 4, 6, 13 -18]. До найбільш ефективних відносять сіткові методи: метод скінченних елементів [7], метод скінченних різниць тощо, та їх проекційно-ітераційні схеми реалізації $[14,15]$, які дозволяють прискорити збіжність процесу отримання розв'язку задачі, суттєво зменшуючи витрати комп'ютерного часу розрахунків.

Питанню визначення НДС пластинчато-оболонкових конструкцій 3 отворами і включеннями при різних зовнішніх навантаженнях присвячено багато публікацій. Виділимо з них такі $[5,8,10,11,12]$. Фундаментальні результати з дослідження розподілу напружень в пластинах і оболонках біля різноманітних отворів отримані Г. М. Савіним і наведені у його монографії [10]. У [8] досліджено вплив підкріплення у вигляді широкого пружного кільця та за дії температурного поля на оболонку 3 отвором; наведені аналітичні розв'язки для випадків різних фоорм отворів. У [11] проведено дослідження концентрації напружень в зрізаній конічній оболонці із композитного матеріалу, яка ослаблена прямокутним отвором. Система розв'язувальних рівнянь отримана на основі застосування деформаційної теорії пластичності анізотропних середовищ, варіаційного рівняння Лагранжа, методів Ньютона, додаткових напружень i скінченних елементів. Дані наведені для трьох варіантів розташування отвору - біля верхньої основи, посередині конуса і біля нижньої основи.

У даній роботі проведено комп'ютерне моделювання та скінченноелементний аналіз НДС тонкостінної циліндричної оболонки з двома прямокутними отворами та чотирма видами підкріплюючих елементів (стрічкові, вертикальні прямокутні, кутові, видовжені прямокутні). Вивчено вплив форми, розмірів та механічних властивостей підкріплюючих елементів на НДС оболонки в зонах локальних концентраторів напружень. Підкріплюючі елементи отворів змодельовані включеннями (вставками) із матеріалу з іншими, ніж основний матеріал оболонки, механічними властивостями. Вважалося, що на границях включень задано умови жорсткого зчеплення.

Постановка задачі. Дана тонкостінна пружна однорідна ізотропна циліндрична оболонка товщини $h$, радіусу $R$, довжини $L$ з двома однаковими прямокутними отворами ( $a, b$ - сторони прямокутників) та включеннями ширини $h_{l}$. Отвори знаходяться на відстані $l=2 a$ між їх центрами. На торцях оболонки задано рівномірне одновісне навантаження розтягу ( $p=$ const), що не призводить до появи пластичних деформацій.

Розглядаються чотири види включень (рис. 1, а - рис. 1, ट).

Ставиться задача про визначення НДС даної оболонки для кожного варіанта включень, знаходження коефріцієнта концентрації напружень (ККН); дослідження впливу форми, розмірів та механічних властивостей підкріплюючих елементів на НДС оболонки в місцях локальних концентраторів напружень; встановлення раціональних параметрів підкріплень, що дають змогу зменшити ККН в оболонці у порівнянні з оболонкою без включень. 


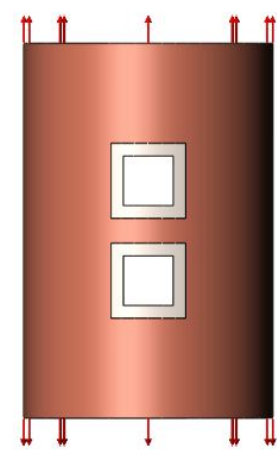

a)

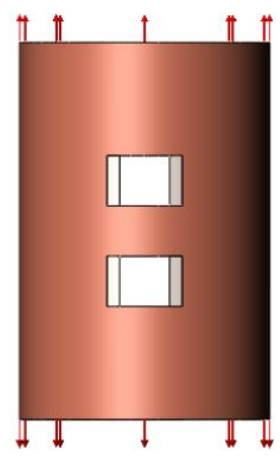

б)

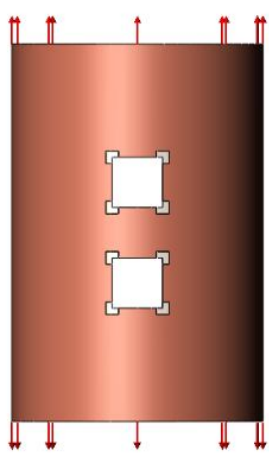

B)

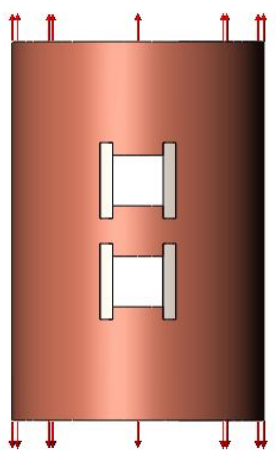

г)

Рис. 1 - Схема навантаження оболонок з включеннями:

а) стрічковими; б) вертикальними прямокутними;

в) кутовими; г) видовженими прямокутними

Математична модель задачі. У варіаційній постановці вихідна задача призводить до мінімізації функціоналу повної потенціальної енергії деформації системи, який у випадку геометрично лінійної теорії тонких оболонок має вигляд [1, 9, 12]:

$$
\begin{gathered}
I[u, v, w]=\frac{h}{2} \sum_{i=1}^{n+1} \int_{\Omega_{i}} \frac{E_{i}}{\left(1-v_{i}^{2}\right)}\left[\left(\frac{\partial u}{\partial \alpha}\right)^{2}+2 v_{i} \frac{\partial u}{\partial \alpha}\left(\frac{\partial v}{\partial \beta}+\frac{1}{R} w\right)+\left(\frac{\partial v}{\partial \beta}+\frac{1}{R} w\right)^{2}+\right. \\
\left.+\frac{1}{2}\left(1-v_{i}\right)\left(\frac{\partial u}{\partial \beta}+\frac{\partial v}{\partial \alpha}\right)^{2}\right] d \alpha d \beta+\frac{h^{3}}{24} \sum_{i=1}^{n+1} \int_{\Omega_{i}} \frac{E_{i}}{\left(1-v_{i}^{2}\right)}\left[\left(\frac{\partial^{2} w}{\partial \alpha^{2}}\right)^{2}+\right. \\
\left.+2 v_{i} \frac{\partial^{2} w}{\partial \alpha^{2}}\left(\frac{\partial^{2} w}{\partial \beta^{2}}-\frac{1}{R} \frac{\partial v}{\partial \beta}\right)+\left(\frac{\partial^{2} w}{\partial \beta^{2}}-\frac{1}{R} \frac{\partial v}{\partial \beta}\right)^{2}+2\left(1-v_{i}\right)\left(\frac{\partial^{2} w}{\partial \alpha \partial \beta}-\frac{1}{R} \frac{\partial v}{\partial \alpha}\right)^{2}\right] d \alpha d \beta- \\
-\int_{\Gamma_{p}}\left(T_{1} u+S_{1} v+Q_{1} w\right) d \beta
\end{gathered}
$$

де $u, v, w$ - переміщення точок серединної поверхні $\Omega$ оболонки в напрямку осей криволінійних координат $\alpha, \beta, \zeta ; R, h$-радіус і товщина циліндричної оболонки; $E_{i}, v_{i}$ - модуль пружності і коефіцієнт Пуассона відповідно (при $i=1)$ матеріалу оболонки (матриці) $\Omega_{1}$ і $(i-1)$-го включення $\Omega_{\mathrm{i}}\left(i=\overline{2, n+1} ; n-\right.$ кількість включень); $\Omega=\bigcup_{\mathrm{i}=1}^{\mathrm{n}+1} \Omega_{\mathrm{i}}-$ область визначення змінних $\alpha, \beta, \zeta ; \Gamma_{p}$ - границя оболонки, на якій діють $T_{1}, S_{1}, Q_{1}$ - крайові поздовжні, поперечні й дотичні зусилля. 
Зазначений фрункціонал (1) можна записати у вигляді [9]

$$
\begin{gathered}
I=h \sum_{i=1}^{n+1} \int_{\Omega_{i}} \frac{G_{i}}{1-v_{i}}\left(\varepsilon_{\alpha}^{2}+2 v \varepsilon_{\alpha} \varepsilon_{\beta}+\varepsilon_{\beta}^{2}+2\left(1-v_{i}\right)\left(\frac{\omega}{2}\right)^{2}\right) d \alpha d \beta+ \\
+\frac{h^{3}}{12} \sum_{i=1}^{n+1} \int_{\Omega_{i}} \frac{G_{i}}{\left(1-v_{i}\right)}\left(\chi_{\alpha}^{2}+2 v \chi_{\alpha} \chi_{\beta}+\chi_{\beta}^{2}+2(1-\tilde{v}) \tau^{2}\right) d \alpha d \beta- \\
-\int_{\Gamma_{p}}\left(T_{1} u+S_{1} v+Q_{1} w\right) d \beta,
\end{gathered}
$$

де $\varepsilon_{\alpha}, \varepsilon_{\beta}, \omega$ - відносні подовження і зсув точок серединної поверхні, пов'язані з координатами $\alpha, \beta ; \chi_{\alpha}, \chi_{\beta}, \tau$ - параметри зміни кручення елемента серединної поверхні; $R$ - радіус циліндричної оболонки; $h$ товщина оболонки; $\Omega=\bigcup_{\mathrm{i}=1}^{\mathrm{n}+1} \Omega_{\mathrm{i}}-$ поверхня оболонки; $\Gamma_{p}-$ границя оболонки, на якій діє навантаження; $G_{i}, v_{i}$ - модуль зсуву і коефріцієнт Пуассона матриці (при $i=1)$ і $(i-1)$-го включення $\Omega_{i}$ (при $i=\overline{2, n+1} ; n-$ кількість включень).

Деформації серединної поверхні, кривини і кручення циліндричної оболонки визначаються за фрормулами [12]:

$$
\begin{gathered}
\varepsilon_{\alpha}=\frac{\partial u}{\partial \alpha}, \quad \varepsilon_{\beta}=\frac{\partial v}{\partial \beta}+\frac{1}{R} w, \omega=\frac{\partial u}{\partial \beta}+\frac{\partial v}{\partial \alpha}, \\
\chi_{\alpha}=-\frac{\partial^{2} w}{\partial \alpha^{2}}, \quad \chi_{\beta}=-\frac{\partial^{2} w}{\partial \beta^{2}}+\frac{1}{R} \frac{\partial v}{\partial \beta}, \\
\tau=-\frac{\partial^{2} w}{\partial \alpha \partial \beta}+\frac{1}{R} \frac{\partial v}{\partial \alpha} .
\end{gathered}
$$

Напруження в серединній поверхні оболонки визначаються співвідношеннями:

$$
\sigma_{\alpha}=\frac{2 G_{i}}{1-v_{i}}\left(\varepsilon_{\alpha}+v_{i} \varepsilon_{\beta}\right), \quad \sigma_{\beta}=\frac{2 G_{i}}{1-v_{i}}\left(\varepsilon_{\beta}+v_{i} \varepsilon_{\alpha}\right), \quad \sigma_{\alpha \beta}=G_{i} \omega .
$$

Функціонал (2) з використанням (3) запишемо у вигляді

$$
I[u, v, w]=h \sum_{i=1}^{n+1} \int_{\Omega_{i}} \frac{G_{i}}{1-v_{i}}\left(\left(\frac{\partial u}{\partial \alpha}\right)^{2}+2 v_{i} \frac{\partial u}{\partial \alpha}\left(\frac{\partial v}{\partial \beta}+\frac{1}{R} w\right)+\left(\frac{\partial v}{\partial \beta}+\frac{1}{R} w\right)^{2}+\right.
$$




$$
\begin{gathered}
\left.+\frac{1}{2}\left(1-v_{i}\right)\left(\frac{\partial u}{\partial \beta}+\frac{\partial v}{\partial \alpha}\right)^{2}\right) d \alpha d \beta+ \\
+\frac{h^{3}}{12} \sum_{i=1}^{n+1} \int_{\Omega_{i}} \frac{G_{i}}{\left(1-v_{i}\right)}\left(\left(\frac{\partial^{2} w}{\partial \alpha^{2}}\right)^{2}+2 v_{i} \frac{\partial^{2} w}{\partial \alpha^{2}}\left(\frac{\partial^{2} w}{\partial \beta^{2}}-\frac{1}{R} \frac{\partial v}{\partial \beta}\right)+\right. \\
\left.+\left(\frac{\partial^{2} w}{\partial \beta^{2}}-\frac{1}{R} \frac{\partial v}{\partial \beta}\right)^{2}+2(1-\tilde{v})\left(\frac{\partial^{2} w}{\partial \alpha \partial \beta}-\frac{1}{R} \frac{\partial v}{\partial \alpha}\right)^{2}\right) d \alpha d \beta- \\
-\int_{\Gamma_{p}}\left(T_{1} u+S_{1} v+Q_{1} w\right) d \beta
\end{gathered}
$$

Інтенсивність деформацій визначається за формулою

$$
\varepsilon_{i}=\frac{2}{3} \sqrt{\frac{1-v+v^{2}}{(1-v)^{2}}\left(\varepsilon_{\alpha}+\varepsilon_{\beta}\right)^{2}-3 \varepsilon_{\alpha} \varepsilon_{\beta}+\frac{3}{4} \omega^{2}} .
$$

У деяких практичних випадках функціонал (1) можна спростити й замість нього розглядати відповідний функціонал теорії пологих оболонок. Це $є$ доцільним, наприклад, при розрахунках НДС оболонкових конструкцій ракетно-космічної техніки з отворами, геометричні параметри більшості з яких такі, що для вивчення НДС в області концентрації напружень біля отворів дозволяють використовувати моделі теорії пологих оболонок.

Метод розв'язування. Для розв'язування отриманої варіаційної задачі застосовано метод скінченних елементів (MCE) [7]. Ідея цього методу при аналізі поведінки конструкції полягає в наступному: суцільне середовище (конструкція в цілому) моделюється шляхом розбиття ії̈ на області (скінченні елементи), у кожній з яких поведінка середовища описується за допомогою окремого набору обраних функцій, що представляють напруження й переміщення в зазначеній області. В межах кожного скінченного елемента здійснюється апроксимація обраної неперервної функції поліномом деякого степеня. Це призводить до заміни вихідної варіаційної задачі дискретною моделлю - системою лінійних або нелінійних алгебричних рівнянь $з$ невідомими значеннями шуканої фрункції у вузлах скінченно-елементної сітки.

Розрахунки здійсненні при застосуванні тетраедральних десятивузлових лагранжевих скінченних елементів другого степеня, при цьому невідомі функції переміщень усередині кожного скінченного елемента апроксимовані квадратичним поліномом. У зонах локальної концентрації напружень (навколо отвору), а також на межі включення і оболонки (матриці) застосовано спеціальним чином підібрану адаптивну сітку. 
Числовий аналіз. Розрахунки проведені на ПК НP Pavilion g6 Notebook PC, AMD Radeon HD 6470M з тактовою частотою 2,2 GHz, оперативною пам'яттю $4 G B$, розрядність системи - х64. Кількість скінченних елементів - 29800, кількість вузлів - 13891. Час розрахунків у середньому $0,5 \times 8$.

Для досліджень використовували циліндричну оболонку длини 0,3 $м$, діаметра $0,2 м$, з квадратними отворами зі стороною $a=b=0,04 \mu$ та чотирма видами включень, при різній ширині включень $h_{1}=a / 4 ; a / 5 ; a / 8$. Відстань між центрами отворів $l=0,08$. Матеріал оболонки - мідь $\left(E_{l}=110\right.$ ГПа, $\left.v_{1}=0,37, \sigma_{02}=258 M \Pi a, \sigma_{6}=394 M \Pi a\right)$; матеріал включень - сталь ( $E_{2}=210$ ГПа, $v_{2}=0,3, \sigma_{02}=620$ МПа, $\left.\sigma_{6}=724 M \Pi a\right)$ або алюміній $\left(E_{3}=70\right.$ ГПа, $v_{3}=0,33, \sigma_{02}=270$ МПа, $\sigma_{6}=470$ МПа). Обрані матеріали носять умовний характер. При комп'ютерному моделюванні вважалось, що між матрицею і включенням задані умови жорсткого зчеплення.

Для зручності проведення числового аналізу було введено величину

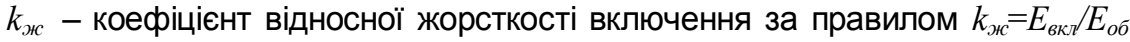
$\left(E_{6 к л}-\right.$ модуль пружності включення, $E_{\text {бб }}$ - модуль пружності матеріала оболонки), і у подальшому під термінами «м'яке» та «жорстке» включення розумілося пружне включення, для якого $k_{\text {ж }}<1$ та $k_{\text {ж }}>1$ відповідно.

У табл. 1 наведено значення ККН для оболонки з одним отвором та стрічковими включеннями (рис. 1, a) для різної ширини включень $h_{l}$.

Таблиця 1 - ККН та відповідні деформації в оболонці 3 одним отвором для випадку рис. 1, а

\begin{tabular}{|c|c|c|c|c|c|}
\hline$k_{*}$ & $h_{1}$ & $\mathrm{KКH}$ & $\delta_{1}, \%$ & $\varepsilon_{i}, 10^{-4}$ & $\delta_{2}, \%$ \\
\hline \multirow{3}{*}{$k_{*}>1$} & $\mathbf{a} / \mathbf{4}$ & $\mathbf{8 , 2 7}$ & $\mathbf{3 8 , 9 9}$ & $\mathbf{3 , 1 9}$ & $\mathbf{- 2 5 , 1 2}$ \\
\cline { 2 - 6 } & $\mathrm{a} / 5$ & 8,61 & 44,71 & 3,09 & $-27,46$ \\
\cline { 2 - 6 } & $\mathrm{a} / 8$ & 8,83 & 48,40 & 3,02 & $-29,11$ \\
\hline \multirow{3}{*}{$k_{*}<1$} & $\mathrm{a} / 4$ & 4,61 & $-22,52$ & 5,58 & 30,99 \\
\cline { 2 - 6 } & $\mathrm{a} / 5$ & 4,58 & $-23,03$ & 5,12 & 20,19 \\
\cline { 2 - 6 } & $\mathbf{a} / \mathbf{8}$ & $\mathbf{4 , 3 5}$ & $\mathbf{- 2 6 , 8 9}$ & $\mathbf{4 , 7 2}$ & $\mathbf{1 0 , 8 0}$ \\
\hline
\end{tabular}

Тут $\delta_{1}, \delta_{2}-$ відхилення ККН та деформацій відповідно в оболонці з одним квадратним отвором та включеннями у порівнянні з випадком для оболонки з отвором без включень.

Аналіз табл. 1 показує, що спостерігається такий механічний ефект:

- в оболонці 3 «жорсткими» включеннями $\left(k_{ж}>1\right)$ має місце деяке збільшення інтенсивності напружень, проте зменшення деформацій (у середньому на 25-30\%) у порівнянні з оболонкою без включень. Для цього виду включень найменші значення максимальних напружень отримано при ширині включень $a / 4$;

- в оболонці з «м'якими» включеннями $\left(k_{ж}<1\right)$ навпаки, спостерігається зменшення інтенсивності напружень в місцях їх концентрації (у середньому на 20-30\%). У той же час, поблизу кутових точок отвору має місце збільшення інтенсивності деформацій. Найменші значення максимальних напружень в цьому випадку - при ширині включень $a / 8$. 
Для різних форм включень, зображених на рис. 1, б - рис. 1, г, отримані аналогічні результати. Незалежно від виду включень, що розглядаються, в оболонках з «жорсткими» включеннями $\left(k_{\text {ж }}>1\right)$ інтенсивність напружень зростає, а деформації зменшуються у порівнянні з результатами для оболонки без включень. Найменші значення максимальних напружень в розглянутих випадках - при ширині включень $a / 4$. В оболонках 3 «м'якими» включеннями $\left(k_{ж}<1\right)$ навпаки, інтенсивність напружень зменшується, а деформації зростають. Найменші значення максимальних напружень тут спостерігаються при ширині включень $a / 8$.

Якщо порівнювати між собою результати для чотирьох розглянутих видів включень, то для «жорстких» включень найменші значення максимальних напружень були отримані у випадку рис. 1, г (видовжені прямокутні включення) при їх ширині $a / 4$. Це проілюстровано на рис. 2.

Для «м'яких» включень найменші значення максимальних напружень були отримані у випадку рис. 1, а (стрічкові включення) при ширині включень $a / 8$. Це подано на рис. 3 .

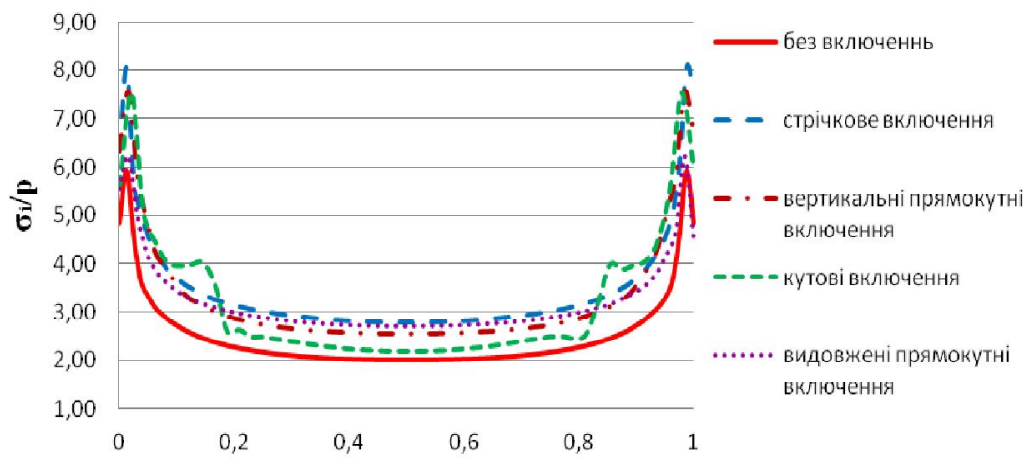

Рис. 2 - Розподіл відносної інтенсивності напружень $\sigma_{\mathrm{i}} / p$ вздовж вертикальної сторони отвору в оболонці 3 квадратним отвором та включеннями при $\mathbf{k}_{\text {ж }}>1$

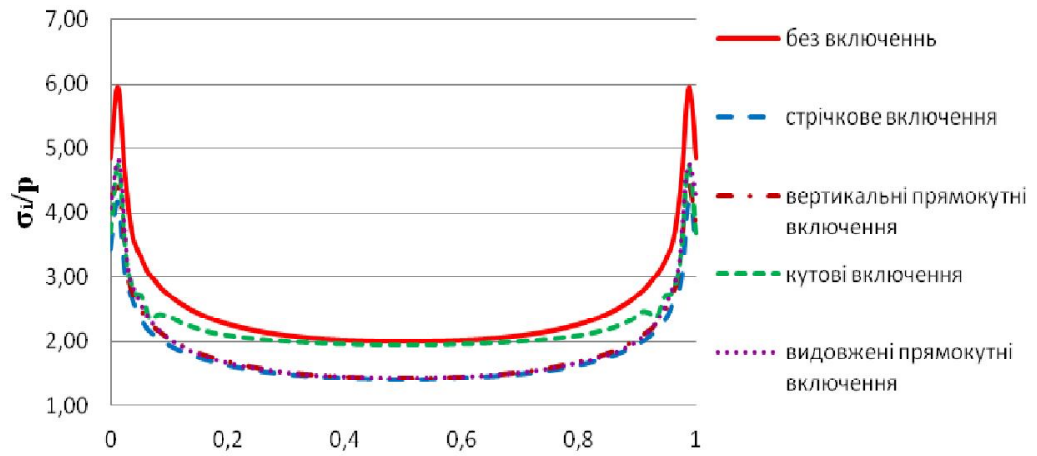

Рис. 3 - Розподіл відносної інтенсивності напружень $\sigma_{i} / p$ вздовж вертикальної сторони отвору в оболонці 3 квадратним отвором та включеннями при $\mathbf{k}_{\text {ж }}<1$ 
Далі, для розрахунків НДС оболонки з двома прямокутними отворами використано знайдені раціональні параметри для «жорстких» і «м'яких» включень у відповідності з отриманими результатами для оболонки з одним отвором, тобто при ширині включень $a / 4$ і $a / 8$ відповідно.

У табл. 2 наведено результати розрахунків ККН для оболонок з двома отворами і чотирма видами включень (рис. $1, a-$ рис. 1, г).

Таблиця 2 - ККН та відповідні деформації в оболонці з двома отворами для випадків рис. 1, a - рис. 1, 2

\begin{tabular}{|c|c|c|c|c|c|c|}
\hline Вид включення & $k_{\text {ж }}$ & $h_{1}$ & КKH & $\delta_{1}, \%$ & $\varepsilon_{i}, 10^{-4}$ & $\delta_{2}, \%$ \\
\hline \multirow[b]{2}{*}{ a) } & $k_{*}>1$ & $a / 4$ & 8,16 & $-2,63$ & 3,22 & 0,94 \\
\hline & $\mathbf{k}_{*}<1$ & $a / 8$ & 4,32 & $-3,36$ & 4,87 & 3,18 \\
\hline \multirow[b]{2}{*}{ б) } & $\mathrm{k}_{*}>1$ & $a / 4$ & 8,06 & $-3,82$ & 3,51 & $-5,90$ \\
\hline & $\mathrm{k}_{*}<1$ & $\mathrm{a} / 8$ & 4,34 & $-2,91$ & 5,22 & $-2,06$ \\
\hline \multirow[b]{2}{*}{ в) } & $\mathrm{k}_{*}>1$ & $a / 4$ & 7,49 & $-2,09$ & 2,77 & 4,53 \\
\hline & $\mathrm{k}_{*}<1$ & $\mathrm{a} / 8$ & 4,54 & $-3,40$ & 5,39 & $-1,82$ \\
\hline \multirow[b]{2}{*}{ 2) } & $k_{*}>1$ & $a / 4$ & 6,53 & $-0,61$ & 2,76 & $-1,08$ \\
\hline & $\mathrm{k}_{*}<1$ & $\mathrm{a} / 8$ & 4,89 & $-1,81$ & 5,25 & $-4,55$ \\
\hline
\end{tabular}

Тут $\delta_{1}, \delta_{2}$ - відхилення ККН та деформацій відповідно в оболонці з двома отворами та включеннями у порівнянні з випадком для оболонки з одним отвором та включеннями.

Із табл. 2 випливає, що за наявністю другого отвору ККН зменшується (на 1-3 \%). При цьому інтенсивність напружень в зоні, що знаходиться ближче до другого отвору, зменшується (на 18-20 \%) у порівнянні з результатами для оболонки з одним отвором. Спостерігається ефект взаємовпливу отворів. Це проілюстровано на рис. 4 і рис. 5.

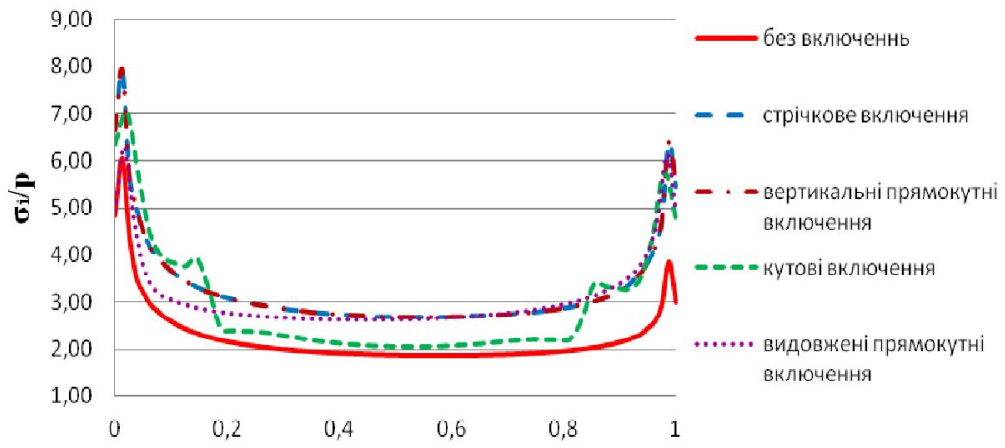

Рис. 4 - Розподіл відносної інтенсивності напружень $\sigma_{i} / p$ вздовж вертикальної сторони отвору в оболонці 3 двома квадратними отворами та включеннями при $\mathbf{k}_{*}>1$ 


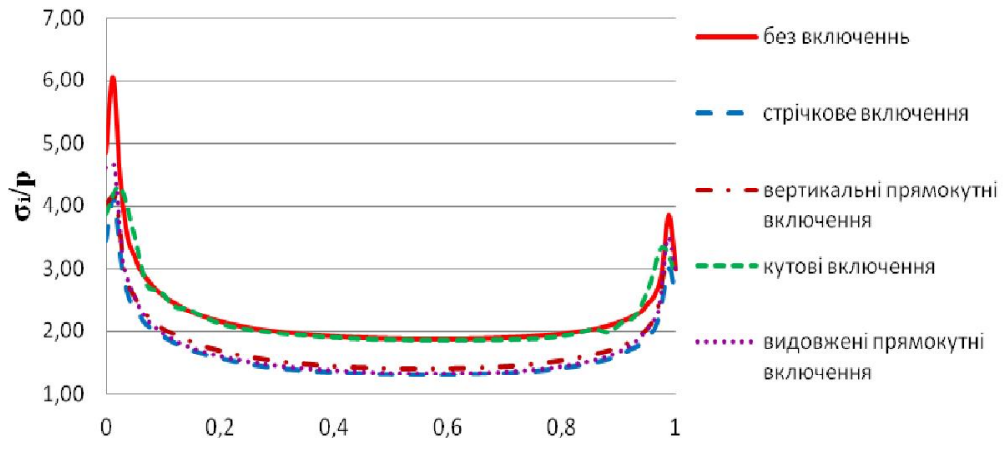

Рис. 5 - Розподіл відносної інтенсивності напружень $\sigma_{i} / p$ вздовж вертикальної сторони отвору в оболонці 3 двома квадратними отворами та включеннями при $\mathbf{k}_{*}<1$

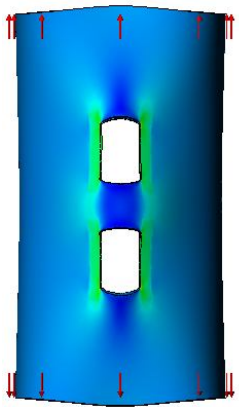

a)

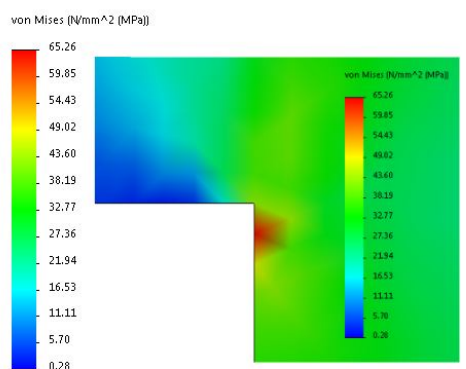

б)

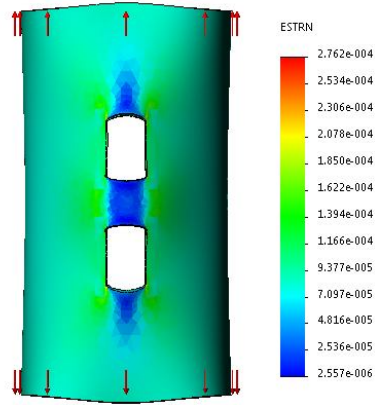

B)

Рис. 6 - Компоненти НДС в оболонці для випадку рис. 1, г при $\mathbf{k}_{\text {ж}}<1$ : а) інтенсивність напружень; б) інтенсивність напружень в околі кута отвору; в) інтенсивність деформацій

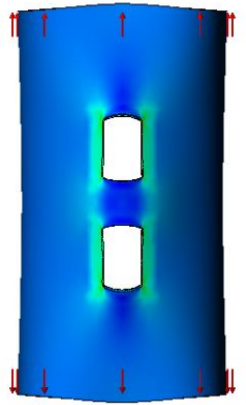

a)

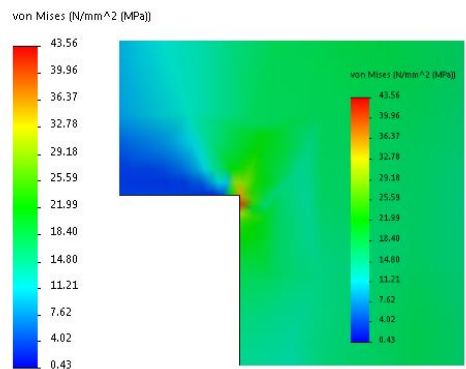

б)

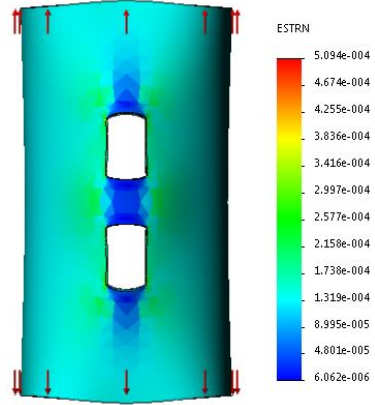

B)

Рис. 7 - Компоненти НДС в оболонці для випадку рис. 1, а при $\mathrm{k}_{\text {ж }}<1$ : а) інтенсивність напружень; б) інтенсивність напружень в околі кута отвору; в) інтенсивність деформацій 
Аналогічно, як і для оболонки з одним отвором, тут у разі «жорстких» включень в оболонці з двома квадратними отворами найменші значення максимальних напружень були отримані у випадку видовжених прямокутних включень (рис. 1, г) при їх ширині $a / 4$. У разі «м'яких» включень найменші значення максимальних напружень спостерігаються у випадку стрічкових включень (рис. 1, а) при їх ширині $a / 8$.

Картини розподілу інтенсивностей напружень і деформацій в оболонці з двома квадратними отворами для цих випадів подано на рис. 6 i рис. 7 відповідно.

Висновки. Результати проведених числових досліджень та їх аналіз дають змогу зробити висновок про суттєвий вплив виду, розмірів і механічних властивостей матеріалу включень на НДС циліндричної оболонки в околі локальних концентраторів напружень.

Так, в оболонці з одним квадратним отвором із розглянутих видів включень навколо отвору найкращим з точки зору зменшення концентрації параметрів НДС виявився випадок видовжених прямокутних включень (рис. 1, г) при ширині включень $a / 4$ у разі використання більш «жорстких» включень ( $\left.k_{ж}>1\right)$, що дало змогу зменшити деформації у середньому на 25-35\%. У разі більш «м'яких» включень $\left(k_{\text {ж }}<1\right)$ найкращим виявився випадок стрічкових включень (рис. 1, а) при ширині включень $a / 8$, при цьому значення ККН можливо зменшити на 20-30\%.

В оболонках з двома отворами спостерігається ефект їх взаємовпливу. При цьому інтенсивність напружень в зоні, що знаходиться ближче до другого отвору, зменшується (на 18-20\%) у порівнянні з оболонкою з одним отвором. ККН зменшується на 1-3\%.

Таким чином, встановлено, що за наявністю в оболонці включень 3 певними механічними властивостями і геометричними параметрами, виникає можливість керувати величиною ККН поблизу локальних концентраторів напружень.

\section{БІБЛІОГРАФІЧНІ ПОСИЛАННЯ}

1. Абовский Н. П., Андреев Н. П., Деруга А. П. Вариационные принципы теории упругости и теории оболочек, М.: Наука, 1978. 288 с.

2. Гарт Э. Л., Клименко Д. В., Рябоконь С. А. Исследование напряженнодеформированного состояния цилиндрических оболочек с прямоугольными вырезом на основе проекционно-итерационных схем реализации метода конечных элементов // Методи розв'язування прикладних задач механіки деформівного твердого тіла: зб. наук. праць. Дніпропетровськ: Ліра, 2011. Вип. 12. С. 47-54.

3. Гарт Э. Л. Конечноэлементный анализ плоскодеформируемых сред с включениями // Вісник Дніпропетр. ун-ту. Сер.: Механіка. 2011. Вип. 15, т. 2. С. 39-47.

4. Гарт Е. Л., Гудрамович В. С. Проекційно-ітераційні схеми реалізації методу скінченних елементів в задачах деформування пластин з отворами та включеннями // Матем. методи і фріз.-мех. поля. 2013. Т. 56, № 2. С. 48-59.

5. Григоренко Я. М., Влайков Г. Г., Григоренко А. Я. Численно-аналитическое решение задач механики оболочек на основе различных моделей, К.: Академпериодика, 2006. 472 с.

6. Гудрамович В. С. Гарт Е. Л., Марченко О. А. Про вплив форми підкріплень на напружено-деформований стан циліндричної оболонки з видовженими прямокут- 
ними отворами // Проблеми обчислювальної механіки і міцності конструкцій: зб. наук. праць. Дніпро: Ліра, 2017. Вип. 27. С. 52-64.

7. Зенкевич О., Морган К. Конечные элементы и аппроксимация / Пер. с англ. М.: Мир, 1986. 318 с.

8. Методы расчета оболочек. В 5 т. Т. 1. Теория оболочек, ослабленных отверстиями / А. Н. Гузь, И. С. Чернышенко, Вал. Н. Чехов и др. К.: Наук. думка, 1980. 636 с.

9. Новожилов В. В., Черных К. Ф., Михайловский Е. И. . Линейная теория тонких оболочек. Л.: Политехника, 1991. 656 с.

10. Савин Г. Н. Распределение напряжений около отверстий. К.: Наукова думка, 1968. $888 \mathrm{c}$.

11. Сторожук $\boldsymbol{\epsilon}$., Максимюк В., Чернишенко І. Про концентрацію напружень в нелінійно-пружній ортотропній конічній оболонці з прямокутним отвором // Актуальні проблеми механіки суцільного середовища і міцності конструкцій / Тези доповідей Другої міжнародної науково-технічної конференції пам'яті академіка НАН України В. І. Моссаковського (до сторіччя від дня народження) (10-12 жовтня 2019 р., Дніпро). Дніпро: 2019. С. 230-231.

12. Цилиндрические оболочки, ослабленные отверстиями / А. Н. Гузь, И. С. Чернышенко, Вал. Н. Чехов и др. К.: Наук. думка, 1974. 272 с.

13. Gudramovich V. S., Gart É. L., Strunin K. A. Modeling of the behavior of planedeformable elastic media with elongated elliptic and rectangular inclusions // Materials Science. 2017. Vol. 52, Iss. 6. P. 768-774.

14. Hart E. L., Hudramovich V. S. Projection-iterative schemes for the realization of the finite-element method in problems of deformation of plates with holes and inclusions // Journal of Mathematical Sciences. 2014. Vol. 203, No. 1. P. 55-69.

15. Hart E. L., Hudramovich V. S. Projection-iterative modification of the method of local variations for problems with a quadratic functional // J. Appl. Math. Mech. 2016. Vol. 80, Iss. 2. P. 156-163.

16. Hart E. L., Hudramovich V. S., Ryabokon'S. A., Samarskaya E. V. Numerical simulation of stress-strain state for nonhomogeneous shell-type structures based on the finite element method // Modeling and Numerical Simulation of Material Science, 2013. Vol. 3, No. 4. P. 155-157.

17. Hudramovich V. S., Hart E. L., KlimenkoD. V., Ryabokon'S. A. Mutual influence of openings on strength of shell-type structures under plastic deformation // Strength of Materials. 2013. Vol. 45, No. 1. P. 1-9.

18. Hudramovich V. S., Sirenko V. N. , Klimenko D. V., Daniev Yu. F., Hart E. L. Development of the Normative Framework Methodology for Justifying the Residual Resource of Starting Buildings' Constructions of Space Launch Vehicles // Strength of Materials. 2019. Vol. 51, Iss. 3. P. 1-8.

\section{УДК 539.3}

Э. Л. Гарт, д-р физ.-мат. наук, Б. И. Терёхин

\section{ВЫБОР РАЦИОНАЛЬНЫХ ПАРАМЕТРОВ ПОДКРЕПЛЯЮЩИХ ЭЛЕМЕНТОВ ПРИ КОМПЬЮТЕРНОМ МОДЕЛИРОВАНИИ ПОВЕДЕНИЯ ЦИЛИНДРИЧЕСКОЙ ОБОЛОЧКИ С ДВУМЯ ПРЯМОУГОЛЬНЫМИ ОТВЕРСТИЯМИ}

Исследовано напряженно-деформированное состояние тонкостенной цилиндрической оболочки с двумя прямоугольными отверстиями и четырьмя видами включений. На основе проведенного конечноэлементного анализа определено влияние формы, размеров и материала включений на напряженно- 
деформированное состояние оболочки в местах локальных концентраторов напряжений. Даны рекомендации по снижению концентрации напряжений.

Ключевые слова: тонкостенная цилиндрическая оболочка, прямоугольные отверстия, включения, подкрепления, напряжения, деформации, коэффрициент концентрации напряжений, метод конечных элементов.

UDC 539.3

\author{
E. L. Hart, Dr. Sci. (Phys.-Math.), B. I. Terokhin
}

\title{
CHOICE OF RATIONAL PARAMETERS OF REINFORCEMENT ELEMENTS IN COMPUTER SIMULATION OF BEHAVIOR OF A CYLINDRICAL SHELL WITH TWO RECTANGULAR HOLES
}

The stress-strain state of a thin-walled cylindrical shell with two rectangular holes and four types of inclusions is investigated. Based on the finite element analysis, the influence of the shape, size and material of inclusions on the stress-strain state of the shell in places of local stress concentrators is determined. Recommendations on reducing stress concentration are given.

Keywords: thin-walled cylindrical shell, rectangular holes, inclusions, reinforcements, stresses, deformations, stress concentration coefficient, finite element method.

Introduction. The elements of thin-walled structures, such as plates and shells, have found wide application in various fields of technology, energy, construction, and others. The integrity of structures is often changed by various types of holes on the basis of various technological considerations. Near the holes, local (additional) stresses arise, which can be several times higher than the main stresses in an element that is not weakened by a concentrator. This initiates destructive processes under certain conditions.

When using inclusions of various geometric shapes and mechanical properties around holes, it becomes possible to influence the stress distribution in the structural element, in particular, the value of the stress concentration coefficient (SCC). Taking into account the presence of such a significant heterogeneity of the material, in turn, leads to an increase in the complexity of the mathematical model of the problem. Therefore, when studying the stress-strain state (SSS) of structures with various inhomogeneities (holes, undercuts, inclusions, etc.) it is advisable to use numerical methods of mechanics: the finite difference method, the local variation method, the finite element method [7] and their projection-iterative implementation schemes $[14,15]$, which allow to accelerate the convergence of the process of obtaining a solution to the problem and significantly reduce the computer calculation time $[2-4,6,13-18]$.

A lot of publications are devoted to the determination of the SSS of plateshell structures with holes and inclusions at various external loads. Let us single out such ones $[5,8,10,11,12]$.

In this work, computer simulation and finite element analysis of the thinwalled cylindrical shell with two rectangular holes and four types of reinforcing elements (tape, vertical rectangular, angular, elongated rectangular) are performed. The influence of the shape, size and mechanical properties of 
the reinforcing elements on the SSS of the shell in the zones of local stress concentrators is studied. The reinforcing elements of the holes are modeled by inclusions (inserts) of material with mechanical properties other than the main shell material. It was believed that the condition of hard adhesion was set at the boundaries of the inclusions.

Numerical analysis. In the case of using inclusions of lower stiffness than the shell material, a decrease in the intensity of stresses in the places of their concentration was established (on average by $20-30 \%$ ). At the same time, an increase in the strain intensity is observed near the corner points of the hole. In the case of the considered "soft" inclusions, the lowest values of the maximum stresses were obtained in the case of tape inclusions.

When using inclusions with a greater rigidity of the material than the main shell material, there is a slight increase in stress intensity, but a decrease in deformations (by an average of 25-35\%). For the considered types of inclusions with greater rigidity of the material, the lowest values of maximum stresses were obtained in the case of elongated rectangular inclusions.

In the presence of a second hole, the SCC decreases (by $\sim 1-3 \%$ ). In this case, the stress intensity in the zone closer to the second hole decreases (by 18-21\%) compared with the shell with one hole. The effect of mutual influence of the holes is observed.

As well as for a shell with one hole, for "hard" inclusions the smallest values of maximum stresses were obtained in the case of elongated rectangular inclusions with their width $a / 4$ ( $a$ is the length of the side of the hole). For "soft" inclusions, the lowest values of maximum stresses were obtained in the case of tape inclusions with their width $a / 8$.

Conclusions. The results of the numerical studies and their analysis allow us to conclude that the type, size and mechanical properties of the material of inclusions significantly affect the SSS of the cylindrical shell in the vicinity of local stress concentrators.

It is established that in the presence of inclusions in the shell with certain mechanical properties and geometric parameters, it becomes possible to control the SCC value near local stress concentrators.

\section{REFERENCES}

1. Abovskii N. P., Andreev N. P., Deruga A. P. Variational principles of the theory of elasticity and the theory of shells. Moscow: Nauka, 1978. 228 p. (in Russian).

2. Hart E. L., Klimenko D. V., Ryabokon S. A. Investigation of the stress-strain state of cylindrical shells with rectangular cuts based on projection-iteration schemes for the implementation of the finite element method // Methods for solving applied problems in solids mechanics: Col. of sci. art. Dnipropetrovsk: Lira, 2011. Vol. 12. P. 47-54. (in Russian).

3. Hart E. L. Finite element analysis of plane-deformable media with inclusions // Bulletin of Dnepropetr. University. Serie: Mechanics. 2011. Vol. 15, iss. 2. - P. 39-47. (in Russian).

4. Hart E. L., Hudramovich V. S. Projection-iterative schemes for implementation of the finite element method in problems of deformation of plates with holes and inclusions // Mathem. methods and phys.-mech. fields. 2013. Vol. 56, No. 2. P. 48-59. (in Ukrainian). 
5. Grigorenko Ya. M., Vlaikov G. G., Grigorenko A. Ya. Numerical and analytical solution of problems of shell mechanics based on various models. Kiev: Akademperiodika, 2006. 472 p. (in Russian).

6. Hudramovich V. S., Hart E. L., Marchenko A. A. Influence of the shape of reinforcements on the stress-strain state of a cylindrical shell with elongated rectangular holes // Problems of Computational Mechanics and Strength of Structures: Col. of sci. art. Dnipro: Lira, 2017. Vol. 27. P. 52-64. (in Ukrainian).

7. Zienkiewicz O., Morgan K. Finite elements and approximation. Moscow: Mir, 1986. 318 p. (in Russian).

8. Methods for calculating shells. In 5 vol. V. 1. Theory of shells weakened by holes / A. N. Guz, I. S. Chernyshenko, Val. N. Chekhov and others. Kiev: Naukova dumka, 1980. 636 p. (in Russian).

9. Novozhilov V. V., Chernykh K. F., Mikhailovskii E. I. Linear theory of thin shells. Leningrad: Polytechnic, 1991. 656 p. (in Russian).

10. Savin G. N. Stress distribution around holes. Kiev: Naukova dumka, 1968. 888 p. (in Russian).

11. Storozhuk E., Maksimyuk V., Chernishenko I. About the concentration of pressure in the non-linear elactic orthotropic conical shell with a straight opening // Actual problems of continuum mechanics and structural strength / Abstracts of the Second International Scientific and Technical Conference in memory of Academician of the NAS of Ukraine V.I. Mossakovskii (on the centenary of his birth) (October 10-12, 2019, Dnipro). Dnipro: 2019. P. 230-231. (in Ukrainian).

12. Cylindrical shells weakened by holes / A. N. Guz, I. S. Chernyshenko, Val. N. Chekhov and others. Kiev: Naukova dumka, 1974. 272 p. (in Russian).

13. Gudramovich V. S., Gart É. L., Strunin K. A. Modeling of the behavior of planedeformable elastic media with elongated elliptic and rectangular inclusions // Materials Science. 2017. Vol. 52, Iss. 6. P. 768-774.

14. Hart E. L., Hudramovich V. S. Projection-iterative schemes for the realization of the finite-element method in problems of deformation of plates with holes and inclusions // Journal of Mathematical Sciences. 2014. Vol. 203, No. 1. P. 55-69.

15. Hart E. L., Hudramovich V. S. Projection-iterative modification of the method of local variations for problems with a quadratic functional // J. Appl. Math. Mech. 2016. Vol. 80, Iss. 2. P. 156-163.

16. Hart E. L., HudramovichV. S., Ryabokon' S. A., Samarskaya E. V. Numerical simulation of stress-strain state for nonhomogeneous shell-type structures based on the finite element method // Modeling and Numerical Simulation of Material Science, 2013. Vol. 3, No. 4. P. 155-157.

17. Hudramovich V. S., Hart E. L., Klimenko D. V., Ryabokon' S. A. Mutual influence of openings on strength of shell-type structures under plastic deformation // Strength of Materials. 2013. Vol. 45, No. 1. P. 1-9.

18. Hudramovich V. S., Sirenko V. N., Klimenko D. V., Daniev Yu. F., Hart E. L. Development of the Normative Framework Methodology for Justifying the Residual Resource of Starting Buildings' Constructions of Space Launch Vehicles // Strength of Materials. 2019. Vol. 51, Iss. 3. P. 1-8.

Дніпровський національний

університет імені Олеся Гончара,

Дніпро, Україна

Надійшла до редколегії 07.09.2019 